\title{
Lung cancer associated with chloromethyl methyl ether manufacture: an investigation at two factories in the United Kingdom
}

\author{
R I McCALLUM, V WOOLLEY, AND A PETRIE
}

From the Department of Occupational Health and Hygiene, University of Newcastle upon Tyne NE2 4AA, $U K$

ABSTRACT The prevalence of deaths from lung cancer, other cancer, and all other causes was studied in workers and former workers at two factories (A and B) in the United Kingdom at which chloromethyl methyl ether has been manufactured, at one since about 1948 and at the other since 1956. At factory A in South Wales 571 men were traced and at factory B in the north east of England 1196. A statistically significant excess of observed deaths from lung cancer but not other cancer compared with the number expected was found in factory $A$ when the death rates for the population of Glamorgan were applied. The deaths from lung cancer at factory $\mathrm{A}$ were related to risk in terms of total exposure time, and average exposure rate and dosage. The degree of exposure was more important than the duration of exposure. There has so far been no demonstrable excess of deaths from lung cancer in employees working at factory $A$ since the process was changed in 1972 . In factory B the risk was low over the whole period, and there was no excess of lung or other cancers compared with the rates for the Tyneside conurbation. Despite improvements in the process in both factories continued surveillance of the workers is needed for some years yet.

Chloromethyl methyl ether (CMME; $\left.\mathrm{CCH}_{2} \mathrm{OCH}_{3}\right)$ is a volatile and highly irritant liquid ${ }^{1}$ that has been used as a methylating agent in organic chemical synthesis in several countries since about 1948. A major use of CMME has been the preparation of ion exchange resins in which a modified polystyrene resin is chloromethylated and then treated with a tertiary amine or polyamine. CMME is synthesised by reacting methyl alcohol, formaldehyde, and hydrochloric acid together using a catalyst, but it may contain between $1 \%$ and $7 \%$ of bischloromethyl ether (BCME; $\mathrm{ClCH}_{2} \mathrm{OCH}_{2} \mathrm{Cl}$ ), a compound now known to be carcinogenic for man.

In 1962 a pronounced excess of lung cancer was suspected and later confirmed ${ }^{2}$ in men (including some relatively young men and non-smokers) who had worked in an area of a Philadelphia factory in which heavy exposure to CMME had occurred. Twelve out of 13 men in whom a histological diagnosis could be made were considered to have oat cell carcinomas. An epidemiological survey of 2285 men

Received 14 September 1982

Accepted 15 November 1982 employed in the factory between 1948 and 1972 showed that lung cancer was 3.8 times higher in workers exposed to CMME than in those not exposed, and that there was a dose response relationship. ${ }^{3}$

Further evidence of human carcinogenesis from a CMME process came from Germany ${ }^{1}$ and Japan. ${ }^{4}$ In 1972 CMME was included in the American Conference of Governmental Industrial Hygienists' (ACGIH) list of threshold limit values as a carcinogen, and in $1973^{5}$ both CMME and BCME were listed as carcinogens ("emergency temporary standard") by the United States of America Occupational Safety and Health Administration and were confirmed the following year. ${ }^{6}$

Nevertheless, in a retrospective epidemiological study of a cohort of 1827 workers exposed to CMME in the United States an increased risk of lung cancer was found at only one firm out of six investigated and this increased risk could be linked to high exposure.?

BCME has been shown to be carcinogenic for mouse skin $^{8}$ and to produce adenomas of the lung 9 in mice. Squamous cell cancer of the lung and 
tumours of the olfactory epithelium (described as esthesioneuroepitheliomas) were produced in rats ${ }^{10}$ after exposures to $0 \cdot 1 \mathrm{ppm}$ BCME for six hours a day, five days a week, for a total of 101 exposures.

\section{Present study}

The deaths of workers employed in the manufacture of chloromethyl methyl ether have been studied in two factories in the United Kingdom, one in South Wales (factory A) and the other in the north east of England (factory B). The aim of the study was to determine whether or not there was excess mortality from lung cancer or nasal cancer among workers who had been employed in either of the two factories at any time since production began up to the end of 1980 , and who might have been exposed to CMME or BCME.

Production of CMME at factory $\mathrm{A}$ began in about 1948 as a batch process. No measurements of CMME or BCME concentrations were made at this time but exposure to these substances may have been high. In 1972 improvements in the process were estimated to have reduced exposures to CMME to low levels. The chemical process in factory B was essentially the same as that in factory A. The severity, however, of the exposure that had occurred in factory B before 1971, when the plant was altered to eliminate exposure to $\mathrm{CMME}$, was estimated to be low.

\section{Methods}

The name and birth date of each man was sent to the National Health Service Central Register (NHSCR) so that the date and cause of death would be notified to us.

The analysis was based on man-years-at-risk, in which the number of deaths observed was compared with that expected. Man-years used in the calculation of the expected deaths were obtained from the sums of the number of years each man contributed to each age group from the time of his first employment at the factory up to 1980 . The man-years-atrisk in 10-year age groups for each year of the study periods were multiplied by the appropriate age specific death rates and then added together. The death rates used were those for the Tyneside conurbation (mean rates for 1971-6) and Glamorgan Urban Area for $1971^{11}$ rather than the overall rate for England and Wales because of regional differences in the mortality rates in the United Kingdom which make comparisons with national rates less valid.

\section{Exposure}

Defonso and Kelton used a crude scale of zero to six for the exposure level in lieu of more accurate measurements, ${ }^{3}$ and analysed their data using a total exposure time (TET) and a time weighted average exposure rating (TWER). These measures were applied so far as possible at factories $A$ and $B$ so that the mortality experience of men with different exposure ratings could be compared between the two factories.

The information available for each man was put on a computer using punched cards. Slight variations in the numbers used in parts of the analysis are due to some of the data being incomplete in the case of a few men. Only men who were traced and whose health service record was flagged by the NHSCR are included in the analysis since it is not known whether the untraced men are alive, or if dead the cause of death. At factory A 68 men could not be traced and at factory B 122 men, mainly because of lack of a birth date or emigration. In factory $B$ several students who were employed for very short periods have not been included.

There were 571 men at factory $A$ and 1196 at factory B who had worked at one time or another in the factories. The data available were dates of birth of each man and date and cause of death; date of first employment and of ceasing employment, and occupation(s) within the factory; the time during which each man could have been exposed to CMME; and the severity of the exposure on the relative scale of zero to six. From these data were calculated total exposure time (TET) for each man, time weighted average exposure rate (TWER) (individual exposures differed in severity at different times, and an average exposure rate was calculated), dosage-that is, TET $\times$ TWER; the years survived from date of first employment to the end of 1980. An arbitrary category of risk which put individuals exposed for any length of time at 5 or 6 on the severity scale as high risk, those at 3 or 4 at medium risk, and those at 1 or 2 at low risk was also used; the unexposed $(0$ rated) group being taken as no risk.

Although the number of years of service in the factory was known for each man in the study as well as his TET, the actual dates during which exposure occurred were not known. Thus as in many cases the TET was only a fraction of the total service, it was impossible to calculate the number of men exposed in a particular year. For this reason no attempt was made to calculate yearly standardised mortality rates.

Within the factory comparisons could be made between exposed and unexposed groups, and within the exposed group subdivision allowed comparisons 
Table 1 No (\%) of deaths in employees at factories $A$ and B

\begin{tabular}{lcc}
\hline Factory $A$ & $\begin{array}{l}\text { Exposed } \\
(276 \text { men })\end{array}$ & $\begin{array}{c}\text { Unexposed } \\
(295 \text { men })\end{array}$ \\
\hline Lung cancer & $10(3.62)$ & $1(0.33)$ \\
All neoplasms & $14(5.07)$ & $4(1.36)$ \\
All causes & $24(8.70)$ & $14(4.75)$ \\
Factory $B$ & $(394$ men $)$ & $(802$ men $)$ \\
Lung cancer & $1(0.25)$ & $8(0.99)$ \\
All neoplasms & $6(1.52)$ & $14(1.75)$ \\
All causes & $19(4.82)$ & $40(4.99)$ \\
\hline
\end{tabular}

of subgroups with different degrees of exposure. The death rates of the exposed and unexposed groups were compared with the death rates for the male population of the region.

Within the factory comparisons were also made between the number of deaths from lung cancer, all malignant neoplasms, and all other causes of death in the unexposed and exposed groups. In addition, causes of death and number of deaths were considered in relation to TET, dosage, and risk.

At factory A one man with lung cancer, who had been at low risk, died of a perforated peptic ulcer and this was coded by NHSCR as the principal cause of death. He is not therefore included in the group with lung cancer.

\section{Results}

Table 1 shows the deaths from lung cancer, all neoplasms, and all causes of death for the exposed and unexposed groups for both factories up to the end of 1980. In factory A there were $10(3.62 \%)$ deaths from lung cancer in the exposed group compared with one $(0.33 \%)$ in the unexposed group. This gives a relative risk of lung cancer for the exposed group of $\mathbf{1 0 \cdot 9 7}$. In factory $B$ there was only one death from lung cancer in the exposed group compared with eight in the unexposed group; none of the differences in causes of death between the exposed and unexposed at factory B was statistically significant. Deaths at this factory from causes other than lung cancer are comparable for the two groups.

The findings at factory $A$ require more detailed attention. There is a trend of increased deaths with increased risk (table 2), especially noticeable in the high risk category where by 1980 six out of 32 (18.8\%) men had died of lung cancer.

For low and medium risk, the deaths from lung cancer were in the 45-54 year age group, whereas for high risk they were in the age range of 35 to 65 and over.

Table 3 relates the cause of death to dosage at factory A. Because of the small number of individuals falling in the higher dosage categories, the last six categories were amalgamated for comparison with the Glamorgan statistics. For the lowest age group in which deaths from lung cancer occur, the dosage values are greater than 30 . The other age groups show dosages less than 30 , with no particular trend being evident. As dosage is TET $\times$ TWER, a high dosage value may be due to a large TET value and a low average rate, or to a shorter TET but a high exposure rate.

Table 4 shows the effects of TET, dosage, and risk by age on the prevalence of lung cancer at factory $A$. All the deaths fall within a TET of $0-15$ years. In the

Table 2 Cause of death and risk at factory A. (Category of risk for each individual was taken as the highest severity reached on the 0-6 scale irrespective of the amount of time the individual spent at that severity of exposure)

\begin{tabular}{|c|c|c|c|c|c|c|c|}
\hline \multirow[t]{2}{*}{ Risk } & \multirow[t]{2}{*}{ No } & \multicolumn{2}{|c|}{ Lung cancer } & \multicolumn{2}{|c|}{ Other neoplasms } & \multicolumn{2}{|c|}{ All other causes } \\
\hline & & No & $\%$ & No & $\%$ & No & $\%$ \\
\hline $\begin{array}{l}\text { No risk } \\
\text { Low risk } \\
\text { Medium risk } \\
\text { High risk }\end{array}$ & $\begin{array}{r}151 \\
141 \\
48 \\
32\end{array}$ & $\begin{array}{l}1 \\
1 \\
3 \\
6\end{array}$ & $\begin{array}{r}0.7 \\
0.7 \\
6.3 \\
18.8\end{array}$ & $\begin{array}{l}3 \\
1 \\
0 \\
2\end{array}$ & $\begin{array}{l}2 \cdot 0 \\
0.7 \\
0 \\
6 \cdot 25\end{array}$ & $\begin{array}{l}8 \\
8 \\
1 \\
0\end{array}$ & $\begin{array}{l}5 \cdot 3 \\
5 \cdot 7 \\
2.0 \\
0\end{array}$ \\
\hline
\end{tabular}

Table 3 Cause of death and dosage at factory $A$

\begin{tabular}{|c|c|c|c|c|c|c|c|}
\hline \multirow[t]{2}{*}{ Dosage } & \multirow[t]{2}{*}{ No } & \multicolumn{2}{|c|}{ Lung cancer } & \multicolumn{2}{|c|}{ Other neoplasms } & \multicolumn{2}{|c|}{ All other causes } \\
\hline & & No & $\%$ & No & $\%$ & No & $\%$ \\
\hline $\begin{array}{l}0 \\
0 \cdot 1-10 \\
11-20 \\
21-30 \\
31-40 \\
41-50 \\
51-60 \\
61-70\end{array}$ & $\begin{array}{r}151 \\
159 \\
39 \\
17 \\
6 \\
2 \\
1 \\
1\end{array}$ & $\begin{array}{l}1 \\
1 \\
5 \\
2 \\
1 \\
1 \\
0 \\
0\end{array}$ & $\begin{array}{l}0.7 \\
0.6 \\
12.8 \\
11 \cdot 8 \\
16.7 \\
50 \cdot 0 \\
0 \\
0\end{array}$ & $\begin{array}{l}3 \\
1 \\
0 \\
0 \\
1 \\
0 \\
0 \\
0 \\
1\end{array}$ & $\begin{array}{c}2 \cdot 0 \\
0 \cdot 6 \\
0 \\
0 \\
16 \cdot 7 \\
0 \\
0 \\
10 \cdot 0\end{array}$ & $\begin{array}{l}8 \\
8 \\
1 \\
0 \\
0 \\
0 \\
0 \\
0\end{array}$ & $\begin{array}{l}5 \cdot 3 \\
5 \cdot 0 \\
2 \cdot 6 \\
0 \\
0 \\
0 \\
0 \\
0\end{array}$ \\
\hline
\end{tabular}


Table 4 Deaths from lung cancer at factory $A$

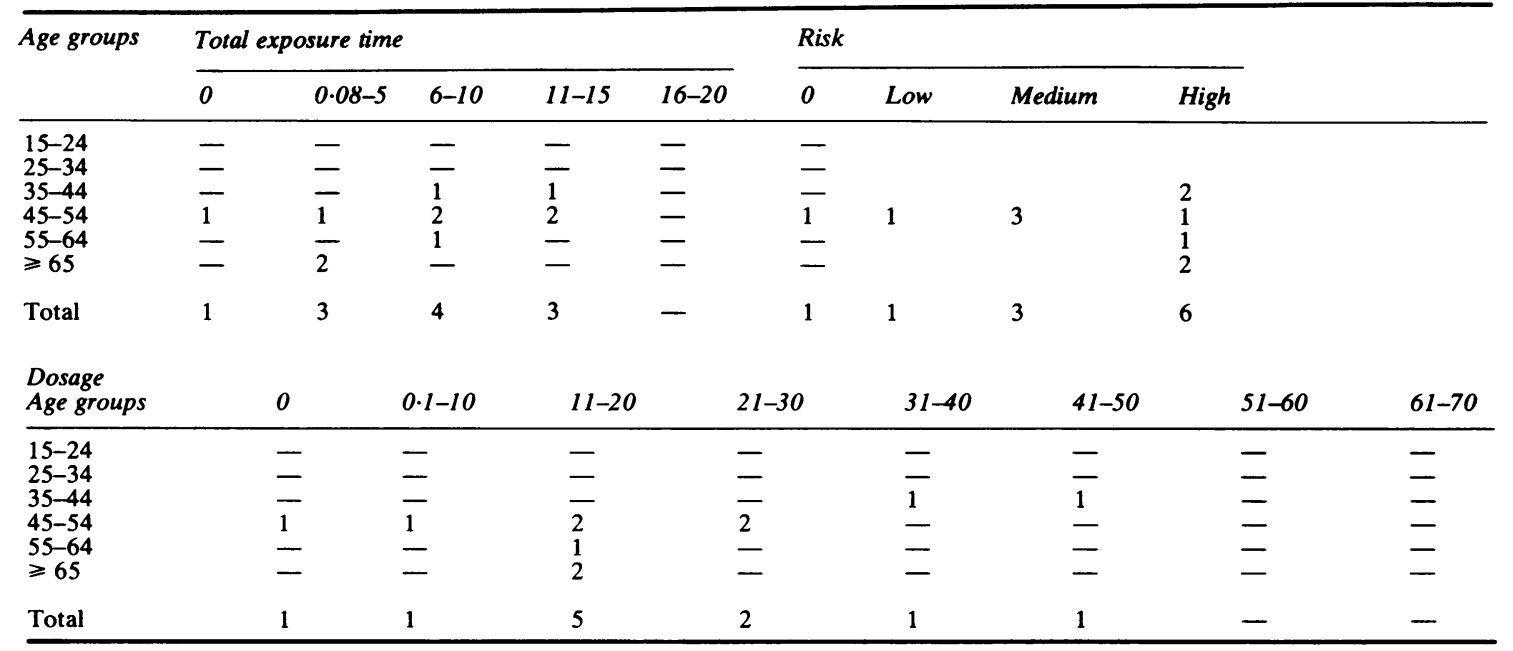

youngest age group (35-44) in which deaths have occurred the men who have been at high risk have had TET values greater than five years, and have high dosage values. On the other hand, the oldest group ( 65 and over) have been at high risk but have TET values of under five years and relatively low dosage values. In their case, apparently, risk rather than the duration of exposure time, is the determining factor. For those aged 45-54 and 55-64 the picture is less clear, but only one death occurs in the no risk category and one in the low risk category, which suggests that both severity and duration of exposure may play a part. Risk of cancer correlates with increased age but with lower dosage.

In the "no risk" group there was only one death from lung cancer in the whole period under study, and the expected number of deaths was 0.994 . The medium risk category showed no significant differences between observed and expected deaths but the number of deaths in the high risk categories was significantly greater than the expected number of deaths, giving an SMR of 597.6 (p <0.001).

Deaths from all malignant neoplasms were also considered by risk categories. The no risk, low risk, and medium risk categories showed non-significant differences between the observed and expected deaths. In the high risk category the seven observed deaths were significantly greater than the 0.778 expected $(p<0.001)$, and five of these deaths were due to lung cancer.

Overall deaths in the exposed and unexposed group were also considered by risk or by dosage category. The unexposed group showed consistently fewer deaths than expected, though not significantly so.
When the exposed group was subdivided into risk categories, the high risk group showed a consistently higher number of observed deaths. The same pattern emerged when dosage was considered.

\section{COMPARISON OF FACTORIES A AND B}

When risk, TET, average exposure rates, and dosage for factory $A$ are compared with those for factory $B$, all the exposed group from factory $B$ fall into the low risk category (fig 1 ). Factory $\mathbf{A}$, however, has $62.8 \%$ of the workers in the low risk category, $21.6 \%$ in the medium risk category, and $15.6 \%$ in the high risk category.

The differences in risk between the two factories were found to be highly significant using the nonparametric Mann-Whitney U test $(p=<0 \cdot 001)$.

The exposure times experienced by individuals in the two factories were similar, with a high percentage in both cases falling into the $0-5$ years category.

Non-significant differences using the MannWhitney U test $(p=0.4)$ were found.

Figure 2 shows that for factory $B$, no average exposures greater than 4 occurred, whereas for factory $\mathrm{A}, 11.9 \%$ of the exposed group had average weighted exposure greater than 3 . The differences are significant using the Mann-Whitney $U$ test $(p=$ 0.006).

For the low dosage categories, the frequencies for the two factories were similar. For factory A, a few workers fell into the higher categories, but the number was extremely small. The differences between the two factories were non-significant $(\mathrm{p}=$ $0 \cdot 5)$. 


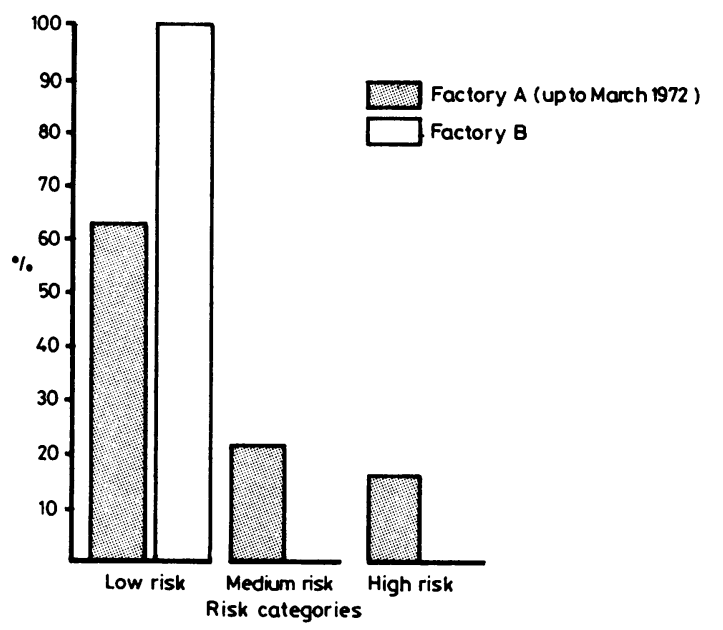

Fig 1 Comparison of risk for exposed groups.

\section{Discussion}

A statistically significant excess in the number of observed deaths from lung cancer has been shown in factory $A$ in men exposed to CMME compared with those who were not. At the lower end of the age range both severity of risk and exposure time appear to be important, but in the oldest group a high degree of risk appears to have been more important than duration of exposure. The SMR for lung cancer (age group 15-64) was 156 for Tyneside conurbation and 92 for Glamorgan Urban Aggregate. ${ }^{1}$ Comparisons of the deaths from lung cancer in factory A with the population of Glamorgan shows an excess in the factory workers, particularly in the high risk group. One man in the exposed group in factory A had nasal cancer but no other examples of nasal cancer were found in either factory.

Exposure to CMME that occurred in factory $B$ produced no greater prevalence of lung cancer than that found in the unexposed group at that factory or in the general male population of Tyneside.

Overall deaths at factory $B$ were found to be fewer than expected, and this may have been due to better general health of the work force compared with that of the male population of the area as a whole. An overall excess of deaths in the high dosage category appears to be due to an excess of accidental deaths since three of seven deaths were due to an accident at the factory. Accidental deaths for this group were significantly higher than for the no dosage and low dosage groups.

Comparison of the results for the two factories show that the most important factor affecting the number of deaths from lung cancer was the degree of exposure to the process rather than the duration of exposure. Both the factors which take time into account (TET and dosage) show similar frequencies for both factories. The average time weighted exposure rates (TWER), however, show frequencies that differ significantly between the two factories, as does the risk, though it must be pointed out that this measure was arbitrary and based on the maximum exposure rating given for each individual.

The absence of excess deaths from lung cancer at factory B in which exposure to CMME was low is consistent with the observations of Pasternack et al. ${ }^{7}$ Even strict control of the process, however, might still entail some exposure, in which case the induction period for lung cancer could be very long.

No account has been taken of smoking habits as it was impossible to determine retrospectively with any accuracy, if at all, what the smoking habits of the two factory populations were.

Pronounced changes were made in the CMME process at factory $A$, in about 1971-2, which falls within the period of exposure (1948-80) studied. The deaths, however, occurred between 1958 and 1980.

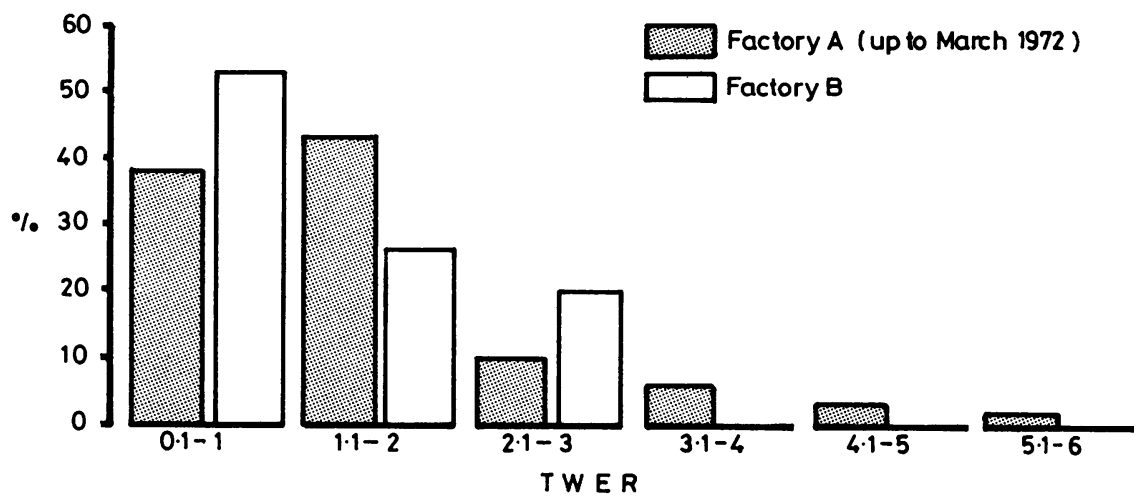

Fig 2 Weighted average exposure rates. 
After 1972 exposure to BCME at factory A was reckoned not to exceed $0 \cdot 1$ on the $0-6$ scale. There were 51 exposed and 144 unexposed men who hac joined the factory after 31 March 1972 and before 31 December 1980. No deaths from lung cancer were recorded in this group. Comparison of the factory deaths with those of the general male population of Glamorgan again showed no significant differences.

The first case of lung cancer to appear in a man who had been exposed at factory $\mathrm{A}$ was diagnosed in 1961 , which is about 13 years after the process first began at the factory. It is only about nine years since the process has been enclosed and monitored in both factories, so that continued surveillance of the factory populations is needed for a further period. The actual period can be estimated only on the basis of the mortality data collected over the next decade or so.

This investigation was supported by a grant from the Commission of the European Community.

Mrs A Petrie was supported by a grant from Messrs Anzon Limited.

We thank Mrs D Weightman, department of medical statistics, University of Newcastle upon Tyne, for her help and advice; also Mrs J Jordan for her help in this study. Mr Graham Sefton and Mr Wastell Anderson have been most helpful in providing the basic data for the factories. Our thanks are also due to the computing laboratory, University of Newcastle upon Tyne.

\section{References}

'Thiess AM, Hey W, Zeller H. Zur Toxikologie von Dichlordimethyläther Verdacht auf Kanzerogene Wirkung auch beim Menschen. Arbeitsmed Arbeitsschutz 1973;23:97-102.

${ }^{2}$ Figueroa WG, Raszkowski $R$, Weiss $W$. Lung cancer in chloromethyl ether workers. N Eng J Med 1973;288:1096-7.

${ }^{3}$ Defonso LR, Kelton SC. Lung cancer following exposure to chloromethyl methyl ether. Arch Environ Health 1976;31:125-30.

4 Sakabe H. Lung cancer due to exposure to bis chloromethyl ether. Ind Health 1973;11:145-8.

${ }^{5}$ Emergency temporary standards for certain carcinogens. Federal Register 1973;38:18900-3.

- Carcinogens. Occupational health and safety standards. Federal Register 1974;39:3768-76.

' Pasternack BS, Shore RE, Albert RE. Occupational exposure to chloromethyl ethers. JOM 1977;19:741-6.

${ }^{8}$ Van Duuren BL, Goldschmidt, BM, Katz C, Langseth L, Mercado G, Sivak A. Alpha haloethers: a new type of alkylating carcinogen. Arch Environ Health 1968;16:472-6.

${ }^{9}$ Leong BKJ, Macfarland HN, Reese WH. Induction of lung adenomas by chronic inhalation of bis (chloromethyl) ether. Arch Environ Health 1971;22:663-6.

${ }^{10}$ Laskin S, Kuschner M, Drew RT, Cappiello VP, Nelson N. Tumours of the respiratory tract induced by inhalation of bis chloromethyl ether. Arch Environ Health 1971;23:135-6.

"Office of Population Censuses and Surveys. Registrar General's decennial supplement. England and Wales, 1971. Area mortality tables. London: HMSO, 1972. 